\title{
On the Performance of Finite Journal Bearings Lubricated With Micropolar Fluids
}

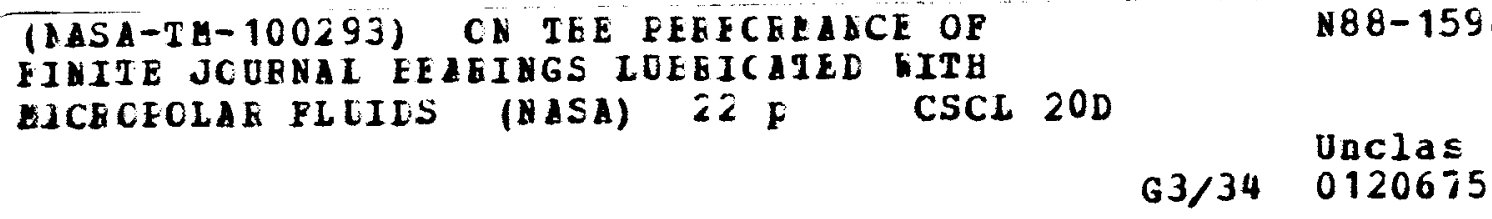

M.M. Khonsari

University of Pittsburgh

Pittsburgh, Pennsylvania

and

D.E. Brewe

Propulsion Directorate

U.S. Army Aviation Research and Technology Activity-AVSCOM

Lewis Research Center

Cleveland, Ohio

Prepared for the

1988 Annual Meeting of the Society of Tribologists and Lubrication Engineers Cleveland, Ohio, May 8-12, 1988 
ON THE PERFORMANCE OF FINITE JOURNAL BEARINGS LUBRICATED

WITH MICROPOLAR FLUIDS

M.M. Khonsari

Department of Mechanical Engineering

University of Pittsburgh

Pittsburgh, Pennsylvania 15261

and

D.E. Brewe*

National Aeronautics and Space Administration

Lewis Research Center

Cleveland, Ohio 44135

\section{ABSTRACT}

A Study of the performance parameters for a journal bearing of finite length lubricated with micropolar fluids is undertaken. Results indicate that a significantly higher load carrying capacity than Newtonian fluids may result depending on the size of material characteristic length and the coupling number. It is also shown that although the frictional force associated with micropolar fluid is in general higher than that of a Newtonian fluid, the friction coefficient of micropolar fluids tends to be lower than that of the Newtonian.

\section{NOMENCLATURE}

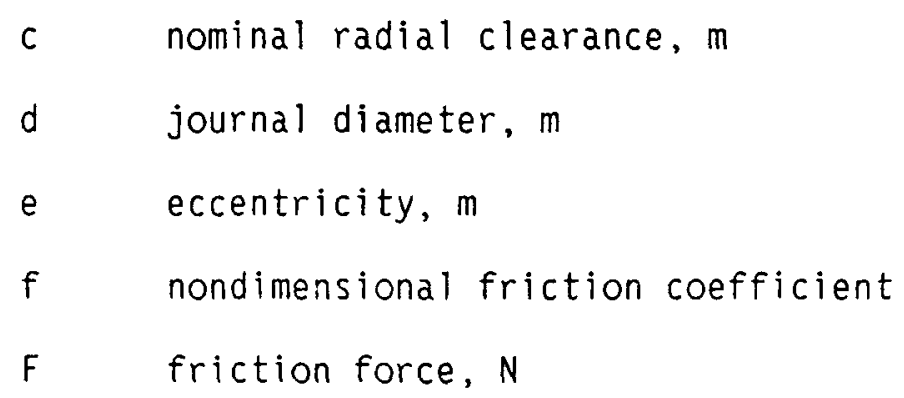

*Member, STLE. 
$\bar{F} \quad$ nondimensional friction force $\frac{c}{\mu U R} F$

h film thickness, $m$

hav film thickness at the point of cavitation, $m$

$h$ nondimensional film thickness $=\frac{h}{c}$

$L$ bearing length, $m$

$\ell_{m} \quad$ nondimensional characteristic length of micropolar fluid $=\frac{c}{\Lambda}$

$N$ coupling number

$P \quad$ hydrodynamic pressure, $N / \mathrm{m}^{2}$

$\bar{P} \quad$ nondimensional pressure $=\frac{p}{\mu} \frac{R}{U}\left(\frac{c}{R}\right)^{2}$

Q leakage flow rate, $\mathrm{m}^{3} / \mathrm{s}$

$\bar{Q} \quad$ nondimensional leakage $=\frac{6 L}{c U R^{2}} Q$

$R$ journal radius, $m$

$W_{R}$ component of load along the radial, $N$

$\bar{W}_{R} \quad$ nondimensional load component $=\frac{W_{x} c^{2}}{\mu U L R^{2}}$

$W_{\varphi} \quad$ component of load along the tangential direction, $N$

$\bar{W}_{\varphi} \quad$ nondimensional load component $=\frac{W_{y} c^{2}}{\mu U L R^{2}}$

W resultant of load, $\mathrm{N}$

$\bar{W}$ nondimensional load $=\frac{W c^{2}}{\mu U L R^{2}}$

$x, y, z$ coordinate system, $m$

$\bar{y} \quad$ nondimensional coordinates $=\frac{y}{L}$

$\gamma$ micropolar viscosity coefficient, $\mathrm{N}-\mathrm{s}$

$\varepsilon$ eccentricity ratio, $\varepsilon=e / c$

$\theta$ nondimensional coordinate, $x / R$ 


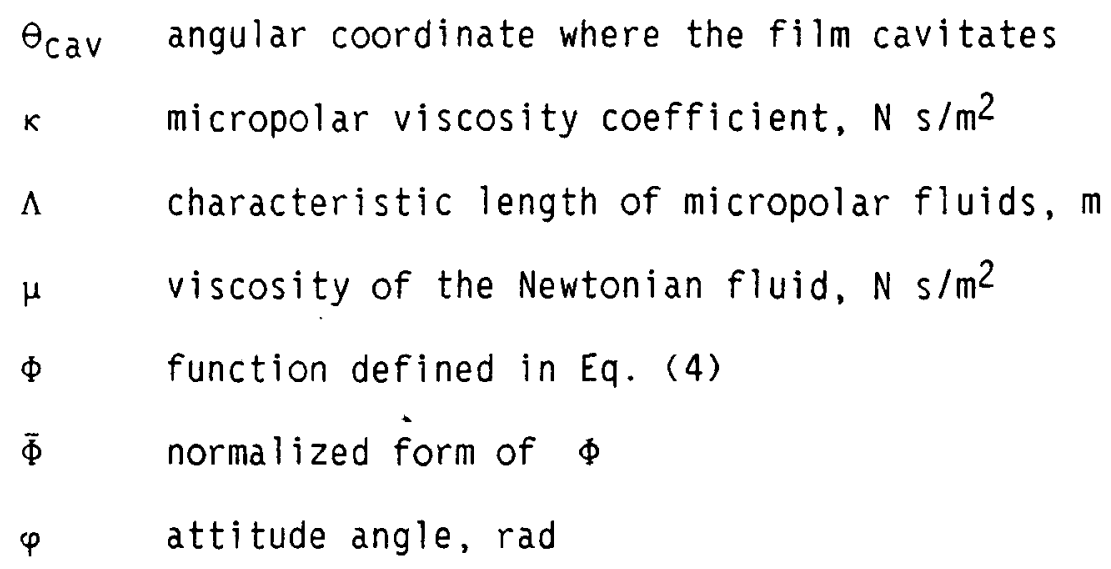

In recent years there has been a considerable amount of interest in the lubricating effectiveness of non-Newtonian fluids. Generally speaking, in non-Newtonian lubricants the shear stresses do not always remain proportional to the shear rates, particularly for high shear rates. To model such fluids, various mathematical formulations such as the power law and Ree-Ering models have been proposed. This paper presents a study of the non-Newtonian behavior of the lubricating oil (in a finite length journal bearing) from the modern continuum point of view. In continuum mechanics, the continuous media is regarded as a set of structured particles possessing individual mass and velocity. These continuum particles are assigned a sub-structure which can translate, rotate, or even deform independently. In other words, the microvolume is considered to have independent microvolume elements that possess individuality.

Theoretical work dealing with the mechanics of fluids with microstructure began with the work of Jeffery (Ref. 1) in 1922 who studied the problem of a Newtonian fluid motion in the presence of suspended ellipsoids. His results indicated that the viscosity of the fluid with such particles was higher than 
that of its base Newtonian fluid. Later in 1957, Prager (Ref. 2) derived constitutive equations for stress in a noninteracting (dilute) dumbbell particle suspension. Since unlike the classical fluid mechanics the microcontinua is regarded as sets of structured particles, the theory required a complete re-examination of the classical concepts that has to be augmented with additional balance laws and constitutive relations.

The general theory of microcontinua is attributed to Eringen who developed the fluid mechanics of deformable microelements (Ref. 3) in an article entitled "Simple Microfluids." The Eringen definition of a simple microfluid is a viscous medium whose behavior and properties are affected by the local motion of particles in its microvolume. These fluids are characterized by 22 viscosity and material constants and when applied to flow problems the result is a system of 19 partial differential equations with 19 unknowns that may not be amenable to solutions. Eringen (Ref. 4) subsequently introduced a subclass of fluids which he named micropolar fluids that ignores the deformation of the microelements but still allows for the particle micromotion to take place. Since then many other papers have appeared in the literature that present different views of the subject based on the continuum mechanics. A comprehensive review of these theories is provided by Ariman et al. (Ref. 5). As for the application of the microcontinuum theory to real flows, the blood rheology appears to be a very promising area (Refs. 6 and 7). Continuum approach to blood flow in the arterioles takes the rotation and deformation of red blood cells into account. Such consideration may be particularly important because of the relative size of the cells as compared with the diameter of the arterioles. Another area where microcontinuum theory may be applied is in the study of rheological behavior of complex microstructures such as liquid crystals which are known to possess complex molecular structure and orientation patterns (Ref. 8). 
Microcontinuum theory in general may also be applied to the study of the non-Newtonian behavior of certain polymer solutions such as polyisobutylene which are known to have long chains of molecular structure. To study such fluids, Hand (Ref. 9) put forward a theory of so called anisotropic fluids and presented theoretical results with comparison to those measured experimentally. Hand showed that theories due to Jeffery (Ref. 1) and Prager (Ref. 2) are contained in his anisotropic fluids as special cases and that the theory can be applied to fluids with microstructure such as polyisobutylene that are spherical at rest but elongate under shear field as do immiscible drops suspended in fluids. Comparing results with experimental measurements, Hand reports good agreement for the dependence of apparent viscosity and normal stress particularly at low shear rates. His success is indicative of the potential of applicability of modern continuum theory for non-Newtonian fluids.

Theoretical works on the non-Newtonian bearings from microcontinuum viewpoint began with the work of Allen and Kline (Ref. 10). They stated that in addition to polymeric fluids with long molecular chains, the continuum model can be used, as a first approximation, for modeling bearings that are contaminated with dirt and particles. Under such conditions, the lubricant can be considered as a fluid suspension. They studied the one-dimensional slider bearing problem and concluded that the theory predicts a higher load capacity and a lower friction coefficient compared to those of a Newtonian fluid, thereby signifying an improvement in the lubrication of a one-dimensional bearing lubricant with micropolar fluids.

Since that article was published, many other papers appeared in the literature that dealt with the lubrication of one-dimensional bearings. To put things in perspective, the following references can be mentioned: for slider or step bearings (Refs. 11 to 17), thrust bearings (Refs. 18 and 19), 
journal bearings (Refs. 20 to 25), squeeze film bearings (Refs. 26 to 30 ), rolling element and elastohydrodynamic lubrication (Refs. 31 and 32).

\section{Governing Equations}

The general form of the governing equations for the steady state motion of micropolar fluids can be written in tensor notation as follows (Ref. 31). conservation of mass:

$$
\nabla \cdot(\rho V)=0
$$

Conservation of linear momentum:

$$
(\lambda+2 \mu) \nabla \nabla \cdot \nabla-\frac{1}{2}(2 \mu+\kappa) \nabla \times \nabla+\kappa \nabla \times v-\nabla \pi+\rho F_{B}=0
$$

Conservation of angular momentum:

$$
(\alpha+\beta+\gamma) \nabla \nabla \cdot v-\gamma \nabla \times \nabla \times v+\kappa \nabla \times v-2 \kappa v+\rho \mathcal{L}_{B}=0
$$

where $V$ is the velocity vector and $v$ is the microrotational velocity vector. $\rho$ is the mass density, $\pi$ is the thermodynamic pressure, $B$ $F_{B}$ is the body force per unit mass, $\mathcal{L}_{B}$ is the body couple (moment) per unit mass, $\mu$ and $\lambda$ are the familiar viscosity coefficients of the classical fluid mechanics, while $\alpha, \beta, \gamma$, and $\kappa$ are additional viscosity coefficients for micropolar fluids.

Equation (2) has the familiar form of the Navier-Stokes equation but it is coupled with Eq. (3) which essentially describes the motion of the particles inside the microvolume as they undergo microrotational effects represented by the microrotational vector $v$. For fluids with no microstructure, this parameter vanishes. For Newtonian fluids, Eqs. (2) and (3) decouple since $k=0$. These equations can be simplified considerably for incompressible fluids ( $\rho=$ constant) in the absence of body forces and inertial forces since 
$\nabla \cdot V=0$ and $F_{B}$ and $\mathcal{L}_{B}$ are assumed to be negligible. Furthermore, the thermodynamic pressure $\pi$ can be replaced by $P$ since:

$$
\pi=-\left[\frac{\partial E}{\partial \rho^{-1}}\right]=P
$$

where $E$ is the internal energy.

Having made the aformentioned assumptions, a so-called generalized

Reynolds equation for micropolar fluids can be derived, see Ref. 14. The resulting equation is given below (Ref. 25):

$$
\frac{\partial}{\partial x}\left[\frac{h^{3}}{\mu} \Phi(N, \Lambda, h) \frac{\partial P}{\partial x}\right]+\frac{\partial}{\partial y}\left[\frac{h^{3}}{\mu} \Phi(N, \Lambda, h) \frac{\partial P}{\partial y}\right]=\frac{U}{2} \frac{\partial h}{\partial x}
$$

where

$$
\begin{gathered}
\Phi(N, \Lambda, h)=\frac{1}{12}+\frac{\Lambda^{2}}{h^{2}}-\frac{N \Lambda}{2 h} \operatorname{coth}\left(\frac{N h}{2 \Lambda}\right) \\
N=\left(\frac{\kappa}{2 \mu+\kappa}\right)^{1 / 2} \\
\Lambda=\left(\frac{\gamma}{4 \mu}\right)^{1 / 2}
\end{gathered}
$$

The parameter $\mu$ is the viscosity of the base fluid as in the case of Newtonian fluids and $\kappa$ and $Y$ are two additional viscosity coefficients for micropolar fluids. These viscosity parameters are grouped in the form of two parameters $N$ and $\Lambda$. $N$ is a dimensianless parameter called the coupling number, for it characterizes the coupling of the linear and angular momentum equations. When $N$ is identically zero, the equations of linear and angular momentum are decoupled and the equation of the linear momentum reduces to the classical Navier-Stokes equation. The parameter $\Lambda$ is called the characteristic length for it characterizes the interaction between the micropolar fluid and the film gap. This parameter, carrying the dimension of 
length, is a function of the size of the lubricant molecule. As $\Lambda$ approaches zero, the effect of microstructure becomes less important and in the limiting case, when $\Lambda$ vanishes, the function $\Phi$ becomes identical to $1 / 12$ and the Reynolds equation reduces to its classical form.

Nondimensionalization

Let:

$$
\ell_{\mathrm{m}}=\frac{\mathrm{c}}{\Lambda} \quad \theta=\frac{\mathrm{x}}{\mathrm{R}} \quad \overline{\mathrm{y}}=\frac{\mathrm{y}}{\mathrm{L}} \quad \bar{h}=\frac{\mathrm{h}}{\mathrm{c}} \quad \overline{\mathrm{P}}=\frac{\mathrm{p}}{\mu} \frac{\mathrm{R}}{\mathrm{U}} \quad \frac{\mathrm{c}}{\mathrm{R}}^{2}
$$

Then the generalized Reynolds equation for micropolar fluids becomes:

$$
\frac{\partial}{\partial \theta}\left[\hbar^{3} \frac{\partial P}{\partial \theta}\right]+\left(\frac{R}{L}\right)^{2} \frac{\partial}{\partial \vec{y}}\left[\hbar^{3} \bar{\phi} \frac{\partial P}{\partial P}\right]=6 \frac{\partial \hbar}{\partial \theta}
$$

where:

$$
\bar{\Phi}=1+12 \frac{1}{l_{m}^{2} h^{2}}-6 N \frac{1}{l_{m}} \operatorname{coth}\left(\frac{N \hbar \ell_{m}}{2}\right)
$$

Boundary conditions are:

$$
\begin{aligned}
\bar{P}=0 & \text { at } \theta=0 \\
\bar{P}=\frac{d P}{d \theta}=0 & \text { at } \theta=\theta_{c a v} \\
\bar{P}=0 & \text { at } \bar{y}=0 \text { and } \bar{y}=1
\end{aligned}
$$

where $\theta=\theta_{\text {cav }}$ is the angular coordinate at which the film cavitates.

Equation (5) is a fully elliptic partial differential equation for which no analytical solution exists. Analytical solutions for a number of bearing configurations are available as cited earlier for either infinitely long bearings $(L / D \gg 1)$ or short bearings $(L / D<1)$. To evaluate the performance of a bearing for a finite length, one must resort to numerical schemes for solution. Equation (5) was solved using the finite difference method: the equation was discretized and the difference equations were solved on a computer using the Successive-Over-Relaxation method (S.O.R.). Convergence was assumed 
when the relative maximum error between two successive iterations fell below a tolerance value of $10^{-3}$. The Reynolds cavitation boundary, conditions were satisfied by setting all negative pressures equal to zero during the computations. Once the pressure distribution was evaluated, the following performance parameters were computed numerically.

Load capacity and attitude angle:

$$
\begin{gathered}
\varpi_{R}=\frac{W_{R} c^{2}}{\mu U L R^{2}}=\iint_{0}^{1} \theta_{0}^{\theta} c a v \cos \theta d \theta d y \\
W_{\varphi}=\frac{W_{\varphi} c^{2}}{\mu U L R^{2}}=\iint_{0}^{1} \theta_{0}^{\theta} c a v \\
W=\frac{W c^{2}}{\mu U L R^{2}}=\sqrt{W_{R}^{2}+W_{\varphi}^{2}} \\
\varphi=\tan ^{-1}\left(-\frac{W_{\varphi}}{W_{R}}\right)
\end{gathered}
$$

Leakage flow rate:

$$
\bar{Q}=\frac{6 L}{C U R^{2}} Q=\int_{0}^{\theta} \operatorname{cav} \bar{\Phi} \hbar^{3} \frac{\partial \bar{P}}{\partial \bar{y}} d \theta
$$

Friction force:

$$
F=\frac{c}{\mu U R} F=\int_{0}^{\theta} \operatorname{cav} A d \theta+\int_{\theta_{c a v}}^{2 \pi} A \frac{\hbar(\theta)}{h_{c a v}} d \theta
$$

where:

$$
A=\frac{\hbar}{2} \frac{d P}{d \theta}+\frac{1}{\hbar-\frac{2 N}{L}\left[\frac{\cosh (N L h)-1}{\sinh (N L h)}\right]}
$$

Friction coefficient:

$$
f\left(\frac{R}{C}\right)=\frac{F}{W}
$$

Equations (7) to (13) were numerically evaluated using a Simpson's integration scheme. 
$\underline{\text { RESULTS }}$

To study the lubricating effectiveness of fluids that exhibit micropolarity, a parametric study was performed. Results are obtained as a function of two-nondimensional parameters, $N$ and $\ell_{m}$ which represent the characteristics of micropolar fluid. Unless otherwise stated, the computations pertain to a finite journal bearing of $L / D=1$.

\section{Pressure Distribution and Load Capacity}

Figure 1 presents a number of three-dimensional pressure profiles for a steadily loaded journal bearing at an eccentricity ratio of $\varepsilon=0.5$.

Figure 1(a) depicts the Newtonian case while Fig. I(b) and (c) show the effect of micropolar lubricant on the pressure distribution. In Fig. 1(b), the nondimensional characteristic length, $\ell_{m}$, was held constant at $\ell_{m}=9.0$ while the coupling number parameter, $\mathrm{N}^{2}$, was varied from 0.1 to 0.9 . Computations indicate that although the shape of the pressure distribution remains the same, the magnitude of the pressure and thus the load capacity varies significantly as a function of the coupling number. From thermodynamic considerations parameter $N$ is limited to $0 \leq N \leq 1$, see Eringen (Ref. 3). At high values of $N$ the effect of microstructures becomes significant whereas at low values

of $\mathrm{N}$ the individuality of the substructure is much less pronounced. In the limiting case, as $N$ approaches zero, the micropolarity is lost and the lubricant is considered to behave as Newtonian. Under such a limiting case, the equation of linear momentum reduces to that of the Navier-Stokes.

The effect of the nondimensional characteristic length on the pressure distribution is depicted in Fig. $I(c)$. As shown, at low $\ell_{m}$, the effect of microstructure is very pronounced. Physically, lower values of $l_{m}$ correspond 
to larger values of the characteristic length $\left(\ell_{m}=c / \Lambda\right.$, where $c$ - the bearing clearance - is assumed to remain constant). Small $\ell_{m}$, therefore, indicates that characteristic length of the substructure is large compared to that of the clearance dimension. At high values of $\ell_{m}$, the effect of substructure becomes less and less significant and in the limiting case when $\ell_{m}$ approaches infinity, the effect of individuality of the microstructure is lost so that the pressure distribution approaches that of the Newtonian.

Variation of the load carrying capacity as a function of the eccentricity ratio, $\varepsilon$, is depicted in Fig. 2 for various values of $N$, keeping the nondimensional characteristic length constant, $\ell_{m}=9$, for all cases. The enhancement in the load capacity for higher values of the coupling number is pronounced. A possible explanation for such phenomena can be attributed to the increase in the viscosity due to the additives, characterized by micropolar fluids. There are some experimental works that support this view. Henniker's extensive review (Ref. 33) entitled, "The Depth of the Surface Zone of a Liquid," (Ref. 33) attest to the evidence of abnormally high viscosity in the vicinity of a solid surface. He refers to some experimental work by Deryagin et al. (Ref. 34) who found the viscosity of a turbine oil within $5000 \mathrm{~A}$ of solid wall to increase tenfold when aluminum naphthionate of up to 2 percent were added in.

Figure 3 depicts how the load carrying capacity varies as a function of $\ell_{m}$ for a number of $N^{2}$, keeping the eccentricity constant. It clearly shows an appreciable rise in the load capacity at small values off $\ell_{m}$ and that the load approaches to that of the Newtonian fluids in the limiting case as $\ell_{m} \rightarrow \infty$. These results are consistent with the analytical solutions due to Cowin (Ref. 35) who showed that for polar fluids in couette flow and Poiseuille flow the effective viscosity $\mu E$ approaches the Newtonian fluid value $\mu$ as $\ell_{\mathrm{m}} \rightarrow \infty$. 


\section{Friction Coefficient}

Variation of the coefficient of friction as a function of eccentricity is shown in Fig. 4 for a number of $N^{2}$ while $l_{m}=9.0$. Also shown is the corresponding variation in friction coefficient for the Newtonian fluid case. This figure indicates that, under the conditions simulated, micropolar fluids exhibit a beneficial effect in that the coefficient of friction is lower than the Newtonian fluids. Furthermore, as the coupling number increases, a lower friction coefficient may result. To further explore this effect, the coefficient of friction was plotted as a function of the $\ell_{m}$ for a number of $N^{2}$ as presented in Fig. 5. This figure clearly shows that micropolar friction coefficient approaches that of Newtonian results as $\ell_{m} \rightarrow 0$ and as $\ell_{m} \rightarrow \infty$ or as $\mathrm{N}^{2} \rightarrow 0$. The most interesting result is that there exists an optimum material length at which the friction coefficient is minimum.

It should be noted that although the friction coefficient of lubricant micropolarity tends to be lower than that of the Newtonian fluids, the friction force tends to be higher as depicted in Fig. 6. The reason for this is of course due to the load capacity of the micropolar fluids increasing more than the corresponding increase in (Fig. 3) which more than compensates for the frictional force. Similar behavior were predicted by analytical work of Allen and $\mathrm{Kline}$ (Ref. 10) for a one-dimensional slider bearing.

\section{CONCLUDING REMARKS}

A study of the lubricating effectiveness of micropolar fluids in a finite journal bearing is presented. Micropolar fluids are a subclass of microfluids in which the fluids exhibit microrotational effects i.e., the fluid is considered to possess microstructure that can rotate independently of the 
microvolume but the deformation (microstretch) is not allowed. These fluids have potential in describing the effect of polymeric additives as the classical Navier-Stokes theory has no provision for the effects of microstructure in fluids.

The results presented in this paper indicate that for a steadily loaded finite journal bearing, the micropolar fluids do indeed exhibit a beneficial effect in that the load carrying capacity is significantly increased and the friction coefficient is less than that of the Newtonian lubricant.

\section{REFERENCES}

1. Jeffery, G.B., 1922, "The Motion of Ellipsoidal Particles Immersed in a Viscous Fluid," Proceedings of the Royal Society of London, Series A, Vol. 102, pp. 161-179.

2. Prager, S., 1955, "Stress Strain Relations in a Suspension of Dumbbells," Transactions, Society of Rheology, Vol. 1, pp. 53-62.

3. Eringen, A., 1964, "Simple Microfluids," International Journal of Engineering Science, Vol. 2, pp. 205-217.

4. Eringen, A., 1966, "Theory of Micropolar Fluids," Journal of Mathematics and Mechanics, Vol. 16, pp. 1-18.

5. Ariman, T., Turk, M.A., and Sylvester, N.D., 1973, "Microcontinuum Fluid Mechanics - A Review," International Journal of Engineering Science, Vol. 11, pp. 905-930.

6. Ariman, T., 1971, "On The Analysis of Blood Flow," Journal of Biomechanics, Vo1. 4, pp. 185-192. 
7. Bugliarello, G., and Sevilla, J., 1970, "Velocity Distribution and Other Characteristics of Steady and Pulsatile Blood Flow in Fine Glass Tubes," Biorheology, Vol. 7, pp. 85-107.

8. Ericksen, J.L., 1967, "Continuum Theory of Liquid Crystals," Applied Mechanics Reviews, Vol. 20, pp. 1029-1032.

9 Hand, G.L., 196i, "A Theory of Anistropic Fluids," Journal of Fluid Mechanics, Vol. 13, pp. 33-46.

10. Allen, S., and Kline, K., 1971, "Lubrication Theory for Micropolar Fluids," Journal of Applied Mechanics, pp. 646-650.

11. Balarm, M., and Sastri, V.V.K., 1972, "Micropolar Lubrication," Journal of Applied Mechanics, Vol. 39, pp. 834-836.

12. Datta, A.B., 1972, "Pivoted Slider Bearing with Convex Pad Surface in Micropolar Fluid," Japanese Journal of Applied Physics, Vol. 11, pp. $98-102$.

13. Maiti, G., 1973, "Composite and Step Slider Bearings in Micropolar Fluid," Japanese Journal of Applied Physics, Vol. 12, pp. 1058-1064.

14. Shukla, J.B., and Isa, M., 1975, "Generalized Reynolds Equation for Micropolar Lubricants and Its Application to Optimum One-Dimensional Slider Bearings: Effects of Solid-Particle Additives in Solution," Journal of Mechanical Engineering Science, Vol. 17, pp. 180-284.

15. Ramaniah, G., and Dubey, J.N., 1977, "Optimum Slider Profile of a Slider Bearing Lubricated with a Micropolar Fluid," Wear, Vol. 42, pp. 1-7.

16. Prakash, J., Tonder, K., and Christensen, H., 1980, "MicropolarityRoughness Interaction in Hydrodynamic Lubrication," Journal of Lubrication Technology, Vol. 102, pp. 368-373. 
17. Sinha, P., and Singh, C., 1981, "The Effect of Additives in the Lubricant of a Composite Bearing with an Inclined Stepped Surface," Wear, Vol. 66, pp. 17-26.

18. Khader, M.S., and Vachon, R.I., 1973, "Theoretical Effects of Solid Particles in Hydrostatic Bearing Lubricant," Journal of Lubrication Technology, Voi. 95, pp. 104-105.

19. Yadav, J.S., and Kapur, V.K., 1981, "Inertial and Fluid Suspension Effects in a Thrust Bearing," Wear, Vol. 66, pp. 9-16.

20. Prakash, J., and Sinha, P., 1975, "Lubrication Theory for Micropolar Fluids and Its Application to a Journal Bearing," International Journal of Engineering Science, Vol. 13, pp. 217-232.

21. Mahanti, A.C., 1976, "A Theoretical Study of the Effect of the Solid Particles in the Lubricant of a Partial Journal Bearing, "Wear, Vol. 39, pp. 45-52 .

22. Prakash, J., and Sinha, P., 1977, "Theoretical Effects of Solid Particles on the Lubrication of Journal Bearings Considering Cavitation," Wear, Vol. 41, pp. 233-249.

23. Zaheeruddin, K., and Isa M., 1978, "Micropolar Fluid Lubrication of OneDimensional Journal Bearings," Wear, Vol. 50, pp. 211-220.

24. Tipei, N., 1979, "Lubrication with Micropolar Fluids and Its Application to Short Bearings," Journal of Lubrication Technology, Vol. 101, pp. 356-363.

25. Sinha, P., Singh, C., and Prasad, K.R., 1981, "Effect of Viscosity Variation Due to Lubricant Additives in Journal Bearings," Wear, Vol. 66, pp. $175-188$.

26. Agrawal, V.K., Ganju, K.J., and Jethi, S.C., 1972, "Squeeze Film and Externally Pressured Bearings Micropolar Fluid Lubricated," Wear, Vol. 19, pp. $259-265$. 
27. Maiti, G., 1974, "Micropolar Squeeze Film Bearing," Japanese Journal of Applied Physics, Vol. 13, pp. 1440-1442.

28. Prakash, J., and Sinha, P., 1976, "Cyclic Squeeze Films in Micropolar Fluid Lubricated Journal Bearings," Journal of Lubrication Technology; Vol. 98, pp. $412-417$.

29. Zaheeruddin, K:, and Isa, M., 1978, "Characteristics of a Micropolar Lubricant in a Squeeze Film Porous Spherical Bearing," Wear, Vol. 51, pp. $1-10$.

30. Sinha, P., 1977, "Dynamically Loaded Micropolar Fluid Lubricated Journal Bearings with Special Reference to Squeeze Films Under Fluctuating Loads," Wear, Vol. 45, pp. 279-292.

31. Prakash, J., and Christensen, H., 1977, "A Microcontinuum Theory for the Elastohydrodynamic Inlet Zone," Journal of Lubrication Technology, pp. 24-29.

32. Sinha, P., 1977, "Effect of Rigid Particles in the Lubrication of Rolling Contact Bearings Considering Cavitation," Wear, Vol. 44, pp. 295-309.

33. Henniker, J.C., 1949, "The Depth of the Surface Zone of a Liquid," Reviews of Modern Physics," Vol. 21, pp. 322-341.

34. Deryagin, B., Stakhovsky, G., and Malyshera, D., 1944, "Measurement of the Viscosity of Wall-adjacent Boundary Layers of Liquids by the Blow-off Method," Acta Physicochim U.R.S.S., Vol. 19, pp. 541-552.

35. Cowin, S.C., 1975, "Limits on the Effective Viscosities of Polar Fluids," The Physics of Fluids, Vol. 17, pp. 2128-2129. 


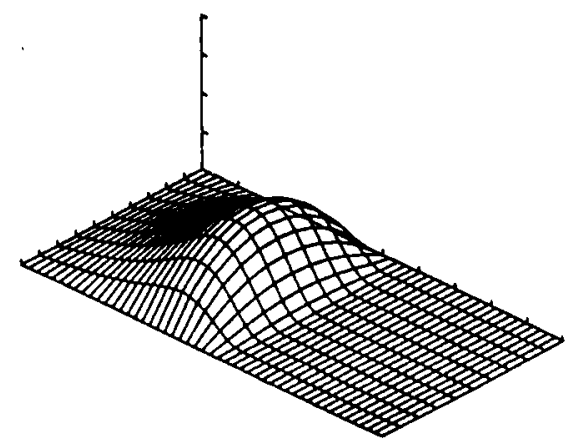

(A) NEWTONIAN.
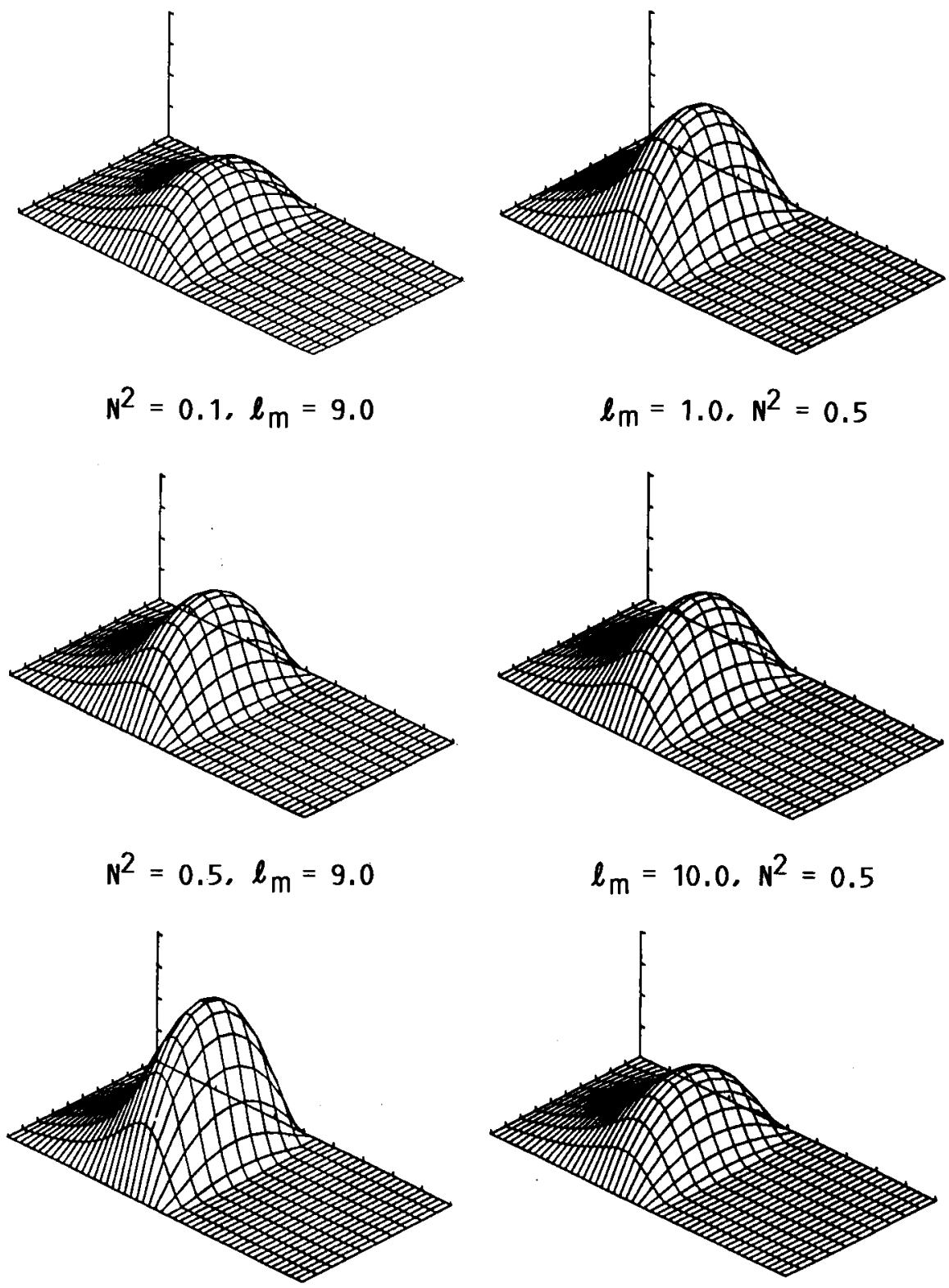

$$
N^{2}=0.9, \ell_{m}=9.0
$$

$$
\ell_{m}=20.0, N^{2}=0.5
$$

(B) EFFECT OF COUPLING NUMBER, $N^{2}$.

(C) EFFECT OF $\ell_{m}$.

FIGURE 1. - PRESSURE DISTRIBUTION FOR NEWTONIAN FLUID AND MICROPOLAR FLUID. $L / D=1, \varepsilon=0.5$. 


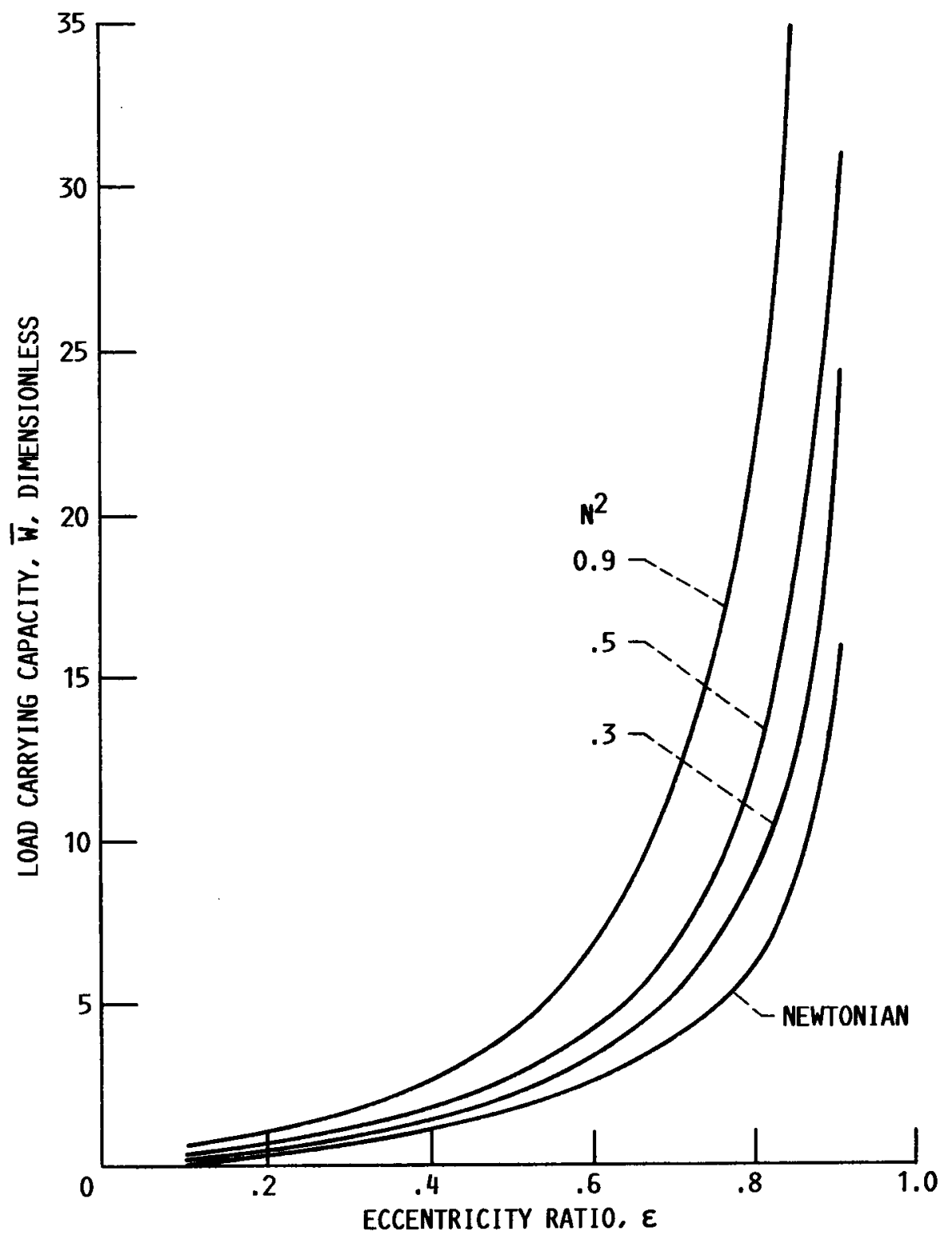

FIGURE 2. - VARIATION OF LOAD CAPACITY AS A FUNCTION OF ECCENTRICITY. $L / D=1, \ell_{m}=9$. 


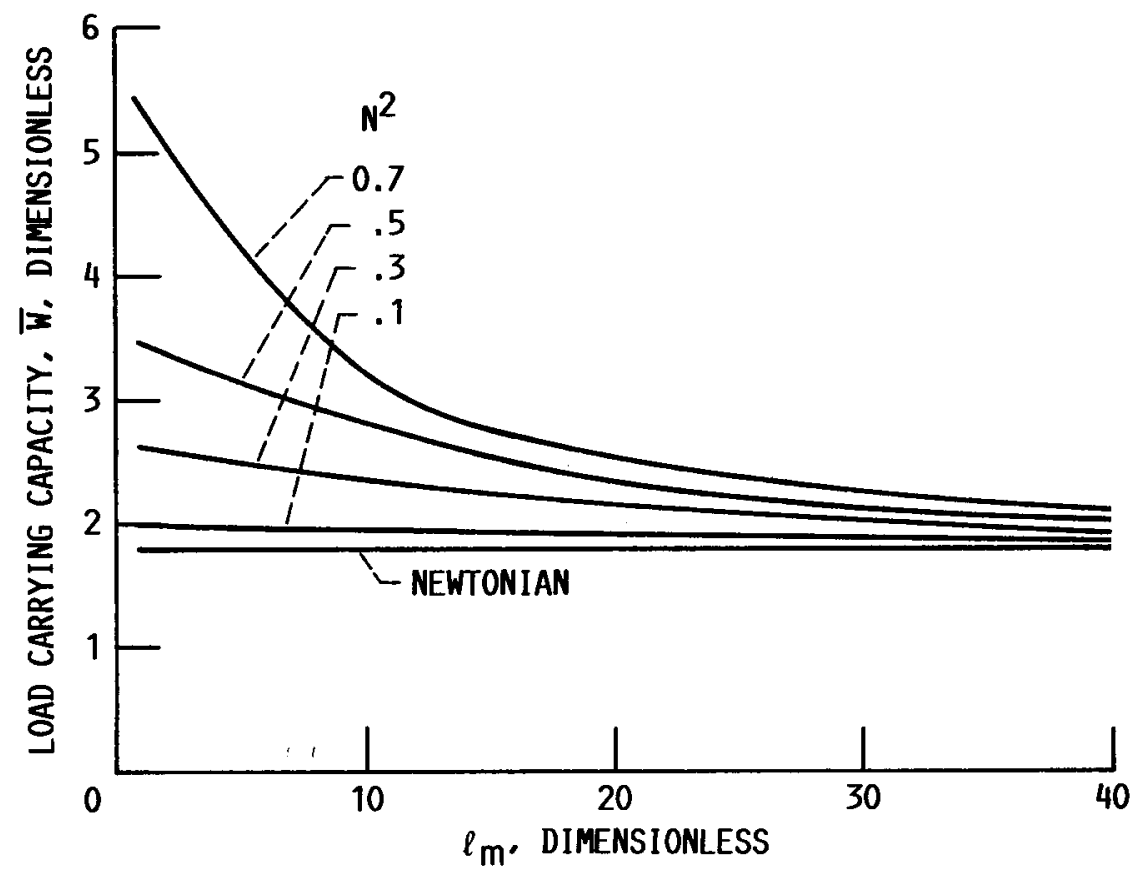

FIGURE 3. - VARIATION OF LOAD CARRYING CAPACITY AS A FUNCTION OF $\ell_{m}$ AND $N^{2} . L / D=1, \varepsilon=0.5$.

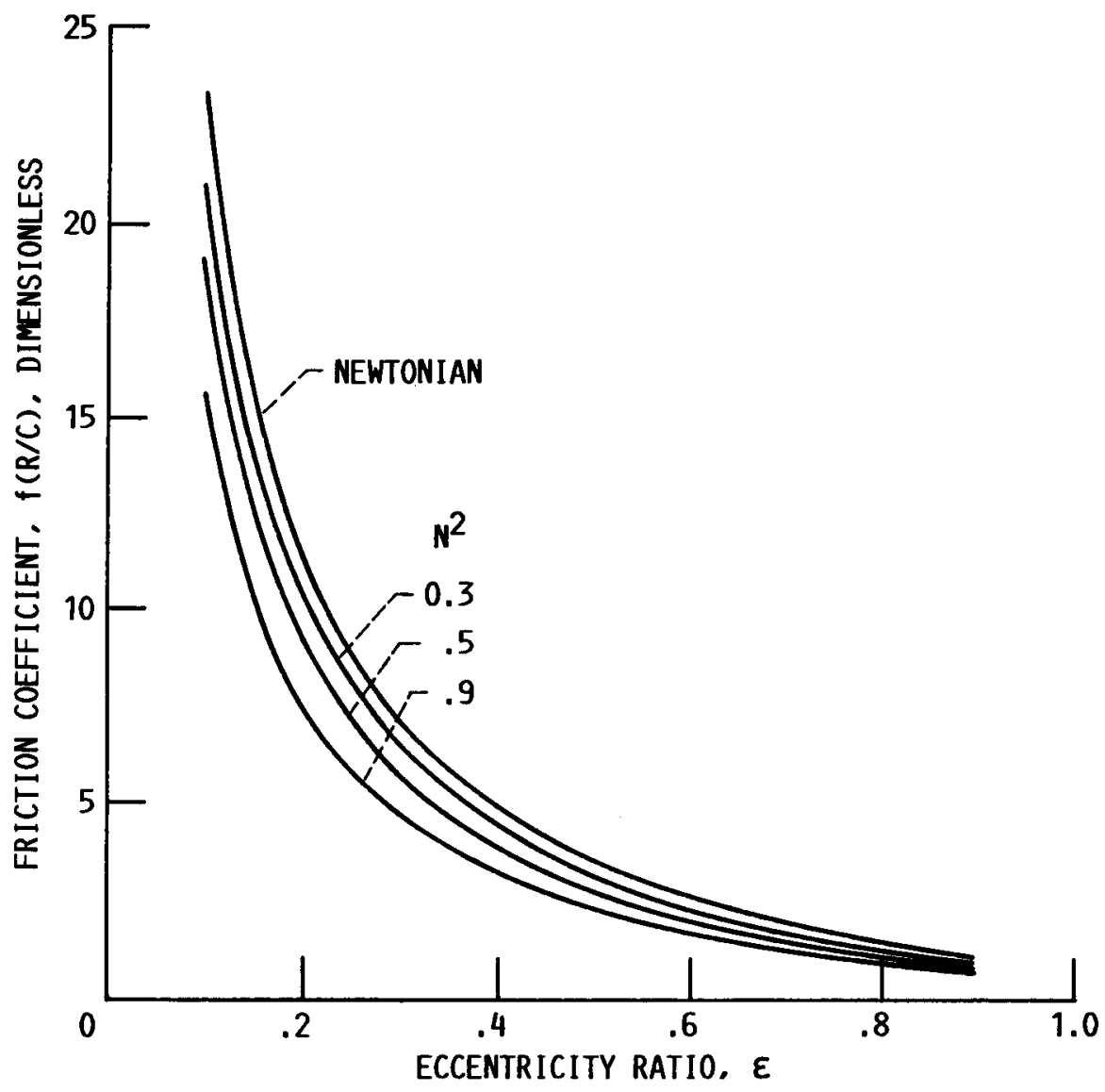

FIGURE 4. - FRICTION COEFFICIENT AS A FUNCTION OF ECCEN-

TRICITY. $L / D=1, \ell_{m}=9$. 


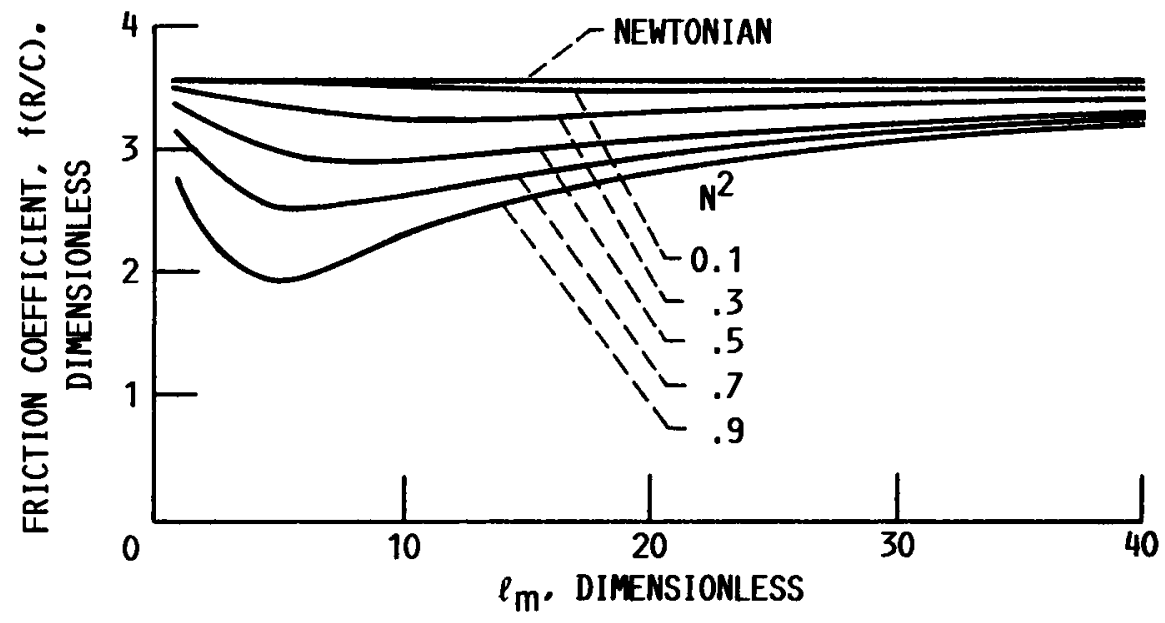

FIGURE 5. - VARIATION OF FRICTION COEFFICIENT AS A FUNCTION OF $\ell_{m}$ AND $N^{2} . \quad L / D=1, \varepsilon=0.5$.

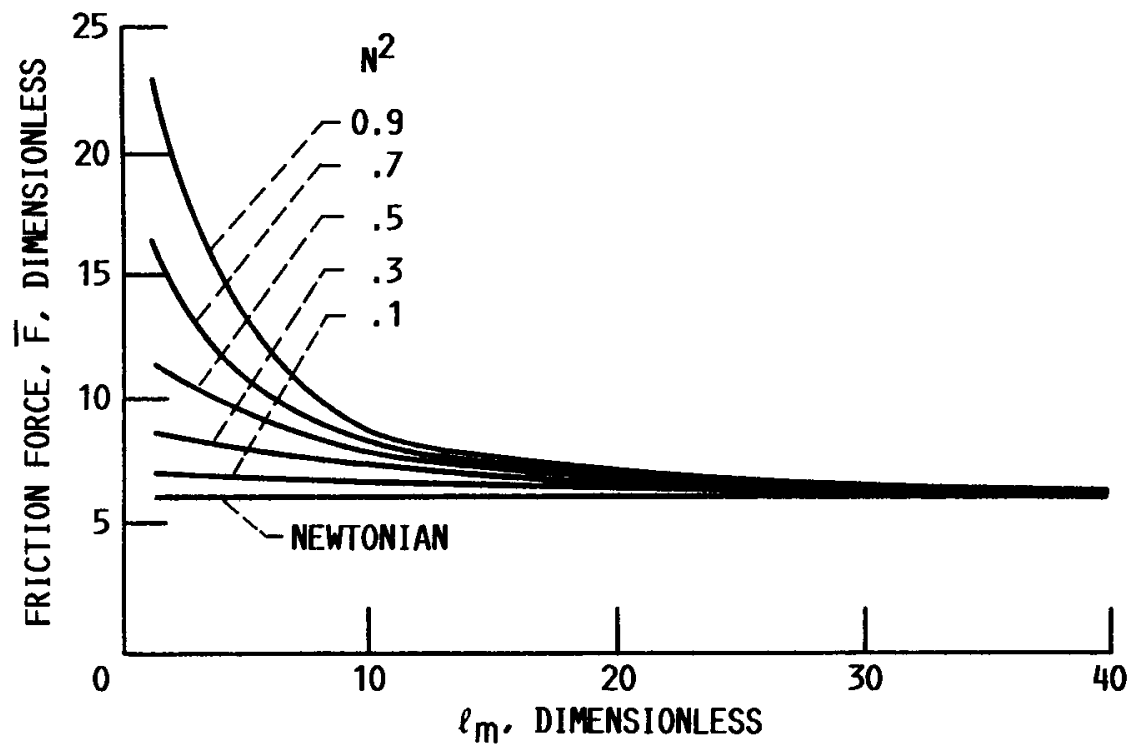

FIGURE 6. - VARIATION OF FRICTION FORCE AS A FUNCTION OF $\ell_{m}$ AND $N^{2} . L / D=1, \varepsilon=0.5$. 


\begin{tabular}{|c|c|c|c|c|}
\hline \multicolumn{5}{|c|}{ Report Documentation Page } \\
\hline $\begin{array}{ll}\text { 1. Report No. } & \text { NASA TM-100293 } \\
& \text { AVSCOM TR-88-C-001 }\end{array}$ & \multicolumn{2}{|c|}{ 2. Government Accession No. } & \multicolumn{2}{|c|}{ 3. Recipient's Catalog No. } \\
\hline \multicolumn{3}{|l|}{ 4. Title and Subtitle } & \multicolumn{2}{|l|}{ 5. Report Date } \\
\hline \multicolumn{3}{|c|}{$\begin{array}{l}\text { On the Performance of Finite Journal Bearings Lubricated } \\
\text { With Micropolar Fluids }\end{array}$} & 6. Performing Organization Code & zation Code \\
\hline \multirow[t]{2}{*}{$\begin{array}{l}\text { 7. Author(s) } \\
\text { M.M. Khonsari and D.E. Brèwe }\end{array}$} & & & \multicolumn{2}{|c|}{$\begin{array}{l}\text { 8. Performing Organization Report No. } \\
\text { E-3939 }\end{array}$} \\
\hline & & & \multicolumn{2}{|l|}{$\begin{array}{l}\text { 10. Work Unit No. } \\
505-63-1 \mathrm{~A}\end{array}$} \\
\hline \multirow{2}{*}{\multicolumn{3}{|c|}{$\begin{array}{l}\text { Cleveland, Ohio } 44135-3191 \\
\text { and } \\
\text { Propulsion Directorate } \\
\text { U.S. Army Aviation Research and Technology Activity-AVSCOM } \\
\text { Cleveland, Ohio 44135-3191 }\end{array}$}} & \multicolumn{2}{|c|}{ 11. Contract or Grant No. } \\
\hline & & & \multirow{2}{*}{\multicolumn{2}{|c|}{$\begin{array}{l}\text { 13. Type of Report and Period Covered } \\
\text { Technical Memorandum }\end{array}$}} \\
\hline \multirow{2}{*}{\multicolumn{3}{|c|}{$\begin{array}{l}\text { 12. Sponsoring Agency Name and Address } \\
\text { National Aeronautics and Space Administration } \\
\text { Washington, D.C. 20546-0001 } \\
\text { and } \\
\text { U.S. Army Aviation Systems Command } \\
\text { St. Louis, Mo. 63120-1798 }\end{array}$}} & & \\
\hline & & & \multicolumn{2}{|c|}{ 14. Sponsoring Agency Code } \\
\hline \multicolumn{5}{|c|}{$\begin{array}{l}\text { Prepared for the } 1988 \text { Annual Meeting of the Society of Tribologists and Lubrication Engineers, } \\
\text { Cleveland, Ohio, May 8-12, 1988. M.M. Khonsari, Department of Mechanical Engineering, University of } \\
\text { Pittsburgh, Pittsburgh, Pennsylvania 15261; D.E. Brewe, Propulsion Directorate, U.S. Army Aviation } \\
\text { Research and Technology Activity-AVSCOM. }\end{array}$} \\
\hline \multicolumn{5}{|l|}{$\begin{array}{l}\text { tepending on the size of material ch } \\
\text { friction coefficient of micropolar flu }\end{array}$} \\
\hline \multicolumn{2}{|c|}{$\begin{array}{l}\text { 17. Key Words (Suggested by Author(s)) } \\
\text { Journal bearings; Micropolar fluids; Lubrication; } \\
\text { Bearings; Non-Newtonian fluids; Microfluids; } \\
\text { Non-Newtonian lubricants; Friction coefficient; } \\
\text { Load capacity }\end{array}$} & \multicolumn{3}{|c|}{$\begin{array}{l}\text { 18. Distribution Statement } \\
\text { Unclassified-Unlimited } \\
\text { Subject Category } 34\end{array}$} \\
\hline $\begin{array}{l}\text { 19. Security Classif. (of this report) } \\
\text { Unclassified }\end{array}$ & 20. Securit & $\begin{array}{l}\text { this page) } \\
\text { assified }\end{array}$ & $\begin{array}{c}\text { 21. No of pages } \\
22\end{array}$ & $\begin{array}{r}\text { 22. Price" } \\
\mathrm{A} 02\end{array}$ \\
\hline
\end{tabular}

